\title{
Compliance with Primary Malaria Chemoprophylaxis: Is Weekly Prophylaxis Better Than Daily Prophylaxis?
}

This article was published in the following Dove Press journal:

Patient Preference and Adherence

\author{
Chaturaka Rodrigo (1) \\ Senaka Rajapakse $\mathbb{D}^{2}$ \\ Sumadhya Deepika \\ Fernando $\left(\mathbb{D}^{3}\right.$ \\ 'Department of Pathology, School of \\ Medical Sciences, UNSW, Sydney, NSW, \\ Australia; ${ }^{2}$ Department of Clinical \\ Medicine, Faculty of Medicine, University \\ of Colombo, Colombo, Sri Lanka; \\ ${ }^{3}$ Department of Parasitology, Faculty of \\ Medicine, University of Colombo, \\ Colombo, Sri Lanka
}

\begin{abstract}
Background: Chemoprophylaxis is an effective tool for individuals to minimize their risk of contracting malaria and serves an important public health role in preventing imported malaria. Yet, it is only effective if the traveller is fully compliant with the prescribed regimen. For many destinations, a choice of prophylactic agents is available, so historical compliance data can be helpful for both physicians and travellers to make an informed decision.
\end{abstract}

Methods: We analyzed the historical self-reported compliance data for six chemoprophylactic agents currently recommended by CDC for primary malaria chemoprophylaxis by searching PubMed, Embase, CINAHL, Web of Science, and Scopus for observational studies reporting on travelers within the last 25 years. The quality of data was graded as "good" or "poor" using the NIH quality assessment tool for cohort and cross-sectional studies. Cumulative compliance data were compiled for all studies (gross compliance) and the subgroup of studies with "good" quality evidence (refined compliance). Subgroup analyses were performed for weekly vs daily administered regimens, between military and civilian travelers, and across each prophylactic agent.

Results: Twenty-four eligible studies assessed compliance for mefloquine $(n=20)$, atovaquone-proguanil $(n=11)$, doxycycline $(n=13)$, and chloroquine $(n=3)$. No studies were found for primaquine or tafenoquine. Both gross and refined compliance were significantly better for weekly regimens than daily regimens $(P<0.0001)$. Stopping chemoprophylaxis due to adverse events was significantly more for doxycycline $(P<0.0001)$ compared to other drugs. Compliance was significantly worse in military travelers, but they were also more likely to be prescribed doxycycline.

Conclusion: Malaria chemoprophylaxis for a traveler should depend on prevailing resistance patterns at destination, current national guidelines, and patient preferences. However, when there is a choice, historical compliance data are useful to select a regimen that the traveler is more likely to comply with.

Keywords: malaria, prophylaxis, compliance, mefloquine, doxycycline, atovaquoneproguanil

\section{Introduction}

There were 228 million malaria cases worldwide in 2018, with Sub-Saharan Africa and India accounting for $85 \%$ of global disease burden. ${ }^{1}$ Of the 405,000 malaria related deaths reported in 2018, 94\% were from Africa. ${ }^{1}$ Pleasingly more countries have reached the state of zero indigenous transmission or elimination in the last decade (eg, Sri Lanka, Uzbekistan, Paraguay). ${ }^{1}$ These countries achieved this milestone by reducing the parasite burden through aggressive surveillance and treatment. Opportune conditions still exist in these countries (eg, the presence of
Correspondence: Chaturaka Rodrigo Department of Pathology, School of Medical Sciences, University of New South Wales (UNSW), 207, Wallace Wurth Building, Sydney 2052, NSW, Australia

Tel +6I 290652186

Email c.rodrigo@unsw.edu.au
Patient Preference and Adherence 2020:14 22I5-2223 in $\square$ 
malaria vector) for onward malaria transmission if the parasite is re-introduced. ${ }^{1}$ Therefore, preventing imported malaria remains a priority for all countries that have eliminated malaria.

Chemoprophylaxis is an effective tool to minimize the risk of malaria while resident in an endemic area, ${ }^{2}$ and may be offered to non-immune travelers moving from a non-endemic area (for malaria transmission) to an endemic area, permanent residents of endemic areas where disease transmission is seasonal, or for special subgroups (children, pregnant women) in areas with year-round malaria transmission. ${ }^{3}$ For non-immune travelers, chemoprophylaxis may be given as primary prophylaxis (a schizonticide agent given before, during, and after travel in an endemic area) or as terminal prophylaxis (hypnozoiticide agent against $P$. vivax given after leaving the endemic area). ${ }^{4}$ For primary prophylaxis, the Centers for Disease Control and Prevention (CDC) recommend mefloquine (weekly dosing), Atovaquone/proguanil combination (daily dosing), doxycycline (daily dosing), chloroquine (weekly dosing), primaquine (daily dosing), and tafenoquine (weekly dosing). ${ }^{5}$ For terminal prophylaxis only primaquine is licensed. However, if tafenoquine is taken as primary prophylaxis, then terminal prophylaxis may be unnecessary. ${ }^{6}$

In this review we aim to compare patient compliance for daily and weekly administered, CDC recommended primary malaria chemoprophylaxis. We also seek to identify associations for better adherence as reported in individual studies. Some drugs and combinations used in the past (eg, proguanil alone, chloroquine/proguanil combination) are no longer recommended by the CDC and will not be considered in this review. In addition, we do not aim to assess the efficacy of chemoprophylaxis or appropriateness of prescription. In each of the studies, the choice of prescription would have been guided by the evidence and national guidelines at the time of prescription.

\section{Methods}

We employed a systematic search strategy to look for eligible studies. These were studies reporting compliance data for CDC recommended primary chemoprophylactic agents after being prescribed to non-immune people temporarily traveling to a malaria endemic area and then returning to their country of origin. The keywords Malaria AND (Mefloquine OR Chloroquine OR Doxycycline OR Primaquine OR malarone OR atovaquone OR proguanil OR Tafenoquine) AND Compliance
AND (Prevention OR Adherance) were used to search PubMed (in all fields), Scopus (in title, abstract, or keywords), Web of Science (in title, abstract, or keywords), CINAHL (in title, abstract, or keywords), and Embase (in all fields). We excluded studies on terminal prophylaxis, intermittent preventive therapy, primary chemoprophylaxis to permanent residents of an endemic region, with travel dates more than 25 years ago (to avoid outdated recommendations), when compliance rates were not reported for each drug, and if the study included an intervention meant to boost compliance apart from standard pre-travel counseling. Unusual dosing regimens of CDC recommended agents were also excluded as these are not normal circumstances that every traveler is exposed to. ${ }^{7}$ Randomized controlled clinical trials ${ }^{8-16}$ were excluded since the strictly controlled patient observations may artificially inflate compliance compared to that observed under "real-world" circumstances. Similarly, case-control studies $^{17}$ that compared malaria patients vs healthy travelers or studies that only reported on returning travelers that contracted malaria ${ }^{18}$ were excluded, as compliance statistics may be skewed by disproportionately low adherence in "cases". We included studies that had gathered data before the chemoprophylaxis regimen was complete (eg, during an overseas military deployment, interviewing travelers at the departure lounge of the destination country), but the quality of evidence from such studies was downgraded. All authors searched the abstracts independently and agreed by consensus on articles for full-text review. The following data items were extracted from eligible studies: time of travel, type of respondents (civil or military travelers), country of origin and destination, interview method, recall time, type of chemoprophylaxis and doses, number of any or serious (leading to hospitalization or stopping the drug) adverse events reported, associations with better or poor compliance, self-reported reasons for poor compliance. The quality of studies was assessed as "good" or "poor" with a modified NHLBI quality assessment tool ${ }^{19}$ for observational cohort and cross-sectional studies (Supplementary Material). Studies that either did not assess the full period of chemoprophylaxis or had a recall time greater than 6 months after completing travel were automatically downgraded as having "poor" quality evidence. Summary statistics (cumulative percentage compliance) were derived with a patient level analysis and compared per chemoprophylactic agent across all studies for self-reported compliance. A subgroup/sensitivity analysis was done based on the following groupings: quality 
of evidence, per individual drug, weekly vs daily prophylaxis, and military vs civilian travelers.

Most eligible studies had defined good compliance as "no doses missed", "> 75\% adherence", and "regular uninterrupted use", while a few noted it as compliant or noncompliant without a definition. Finding similar comparable statistics from individual studies was challenging due to this heterogeneity in reporting results. The studies that did not define their criteria for compliance were downgraded in the quality assessment. In this paper we report two summary statistics on compliance. The first (referred to as gross compliance) is derived from all included studies and includes travelers reporting the highest level of compliance (as defined in each study) over the total number of travelers receiving a drug. The second statistic (referred to as refined compliance) is calculated in the same manner but only from studies categorized as having "good" quality of evidence. In analyzing adverse events (which some studies report as side-effects), it is difficult and inappropriate to link each complaint causally to chemoprophylaxis as these are self-reported data influenced by recall. Hence, we only report the number of travellers that experienced adverse events without detailing type of adverse events. However, from the perspective of patient adherence, if the drug was stopped by the patient due to adverse events, this is a significant and reliable outcome that we have analyzed and compared across different chemoprophylaxis regimens.

\section{Results}

The database search had 1,070 hits (date of search: July 4, 2020). After removal of duplicates, reviews, editorials, opinion papers, animal studies, clinical trials, and case-control studies, 102 articles were identified for full-text review, of which 98 were reviewed. The final number of eligible studies was 24 (Figure 1). Of these, 20 studies reported on mefloquine, ${ }^{20-39}$ three on chloroquine, ${ }^{20,30,32} 11$ on atovaquone/proguanil, ${ }^{23,24,27,30,34-37,40-42} 13$ on doxycycline,$20,21,23-25,30,34-39,43$ and none on primaquine or tafenoquine. Six of the included studies ${ }^{20,21,27,32,33,36}$ also reported on proguanil or chloroquine/proguanil combination, but these groups were excluded from the analysis. Seventeen studies reported on compliance for the entire duration of chemoprophylaxis (pretravel, travel and posttravel), while in the remainder, the participants were interviewed during travel. ${ }^{20-25,39}$ Ten studies reported on military travelers, ${ }^{22-25,28-30,39,40,43}$ and the rest on civilian travelers. All studies gathered data by self-report (via a

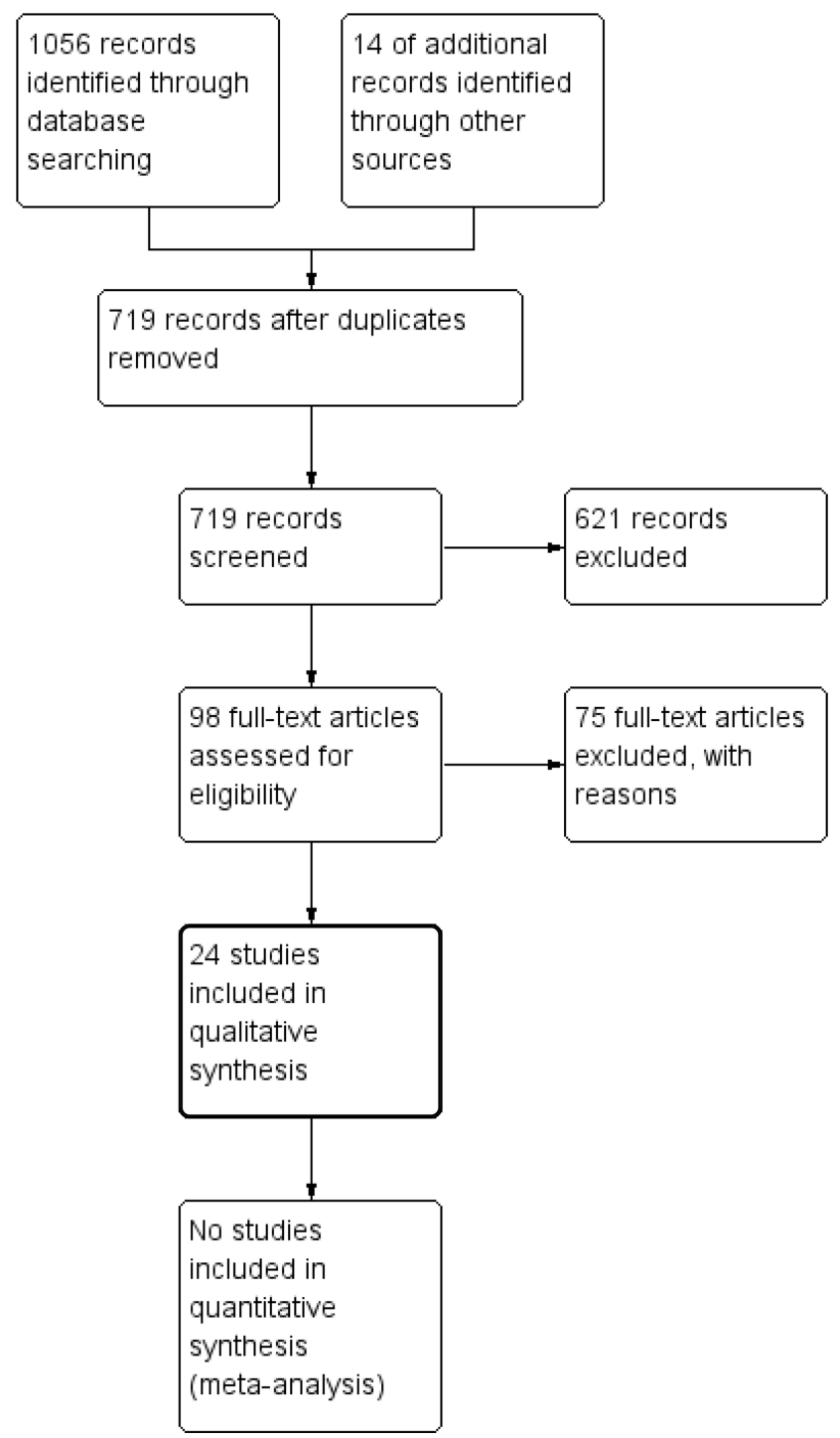

Figure I PRISMA flow chart of literature search for this review.

structured interview questionnaire administered in person, over the phone, or online), while one study $^{31}$ monitored tablet usage via an electronic pillbox and correlated it with patient-reported usage. A summary of included studies is provided in Table 1 . In the quality assessment, 11 studies $^{27,31-38,40,41}$ met the criteria for "good" quality evidence and data from these were used to calculate refined compliance.

\section{Weekly Prophylaxis Mefloquine}

Chemoprophylaxis with mefloquine is recommended to be started 1-2 weeks before travel at a dose of $250 \mathrm{mg}$ per week up until 4 weeks after travel. The total number of travelers prescribed mefloquine was 16,959 (median per 
Table I Characteristics of Included Studies

\begin{tabular}{|c|c|c|c|c|c|c|c|c|}
\hline Study & $\begin{array}{l}\text { Full Period } \\
\text { of } \\
\text { Prophylaxis } \\
\text { Assessed }\end{array}$ & $\begin{array}{l}\text { Is Recall } \\
\text { Period Less } \\
\text { Than } 6 \\
\text { Months? }\end{array}$ & $\begin{array}{l}\text { Drugs for } \\
\text { Which } \\
\text { Compliance } \\
\text { Data are } \\
\text { Reported* }\end{array}$ & $\begin{array}{l}\text { Civil (C) } \\
\text { or } \\
\text { Military } \\
\text { (M) } \\
\text { Travelers }\end{array}$ & $\begin{array}{l}\text { Country } \\
\text { Traveling } \\
\text { from }\end{array}$ & $\begin{array}{l}\text { Country } \\
\text { Traveling } \\
\text { to }\end{array}$ & $\begin{array}{l}\text { Is the } \\
\text { Total } \\
\text { Number of } \\
\text { Travelers } \\
\text { with } \\
\text { Adverse } \\
\text { Events } \\
\text { Reported } \\
\text { per Drug? }\end{array}$ & $\begin{array}{l}\text { Reviewers } \\
\text { Assessment } \\
\text { Grade of } \\
\text { Quality** }\end{array}$ \\
\hline Belderok et al $2013^{27}$ & Yes & Yes & $M, A$ & C & Netherlands & Various & Yes & Good \\
\hline Bellanger et al $2011^{43}$ & Yes & Yes & $D$ & M & France & $\begin{array}{l}\text { Cote D' } \\
\text { Ivoire }\end{array}$ & No & Poor \\
\hline DePetrillo et al $2010^{41}$ & Yes & Yes & A & C & USA & Various & Yes & Good \\
\hline Frickmann et al $2013^{23}$ & No & Not applicable & $M, A, D$ & M & Germany & Various & No & Poor \\
\hline Fujii et al $2007^{28}$ & Yes & Not reported & $M$ & M & Japan & East Timor & Yes & Poor \\
\hline Goodyer et al $2011^{37}$ & Yes & Yes & $M, A, D$ & C & UK & Various & Yes & Good \\
\hline Hoebe et al $1997^{33}$ & Yes & Yes & M & C & Netherlands & Various & No*** & Good \\
\hline Hoefnagel et $\mathrm{al}^{20,34}$ & Yes & Yes & M, A, D & C & Netherlands & Various & No & Good \\
\hline Landman et al $2015^{24}$ & No & Not applicable & M, A, D & M & Various & $\begin{array}{l}23 \text { African } \\
\text { countries }\end{array}$ & Yes & Poor \\
\hline Landry et al $2006^{31}$ & Yes & Yes & M & C & Switzerland & Various & Yes & Good \\
\hline Laver et al $200 \mathrm{I}^{20}$ & No & Not applicable & $M, D, C$ & C & Various & Zimbabwe & No & Poor \\
\hline Lobel et al $200 \mathrm{I}^{21}$ & No & Not applicable & $M, D$ & C & Various & Kenya & Yes & Poor \\
\hline Matsumura et al $2005^{26}$ & Yes & No & M & C & Japan & Various & Yes & Poor \\
\hline $\begin{array}{l}\text { Mavrogordato et al } \\
2012^{36}\end{array}$ & Yes & Not reported & M, A, D & C & Various & Ethiopia & No & Good \\
\hline Nicosia et al $2008^{42}$ & Yes & Not reported & A & C & Italy & $\begin{array}{l}\text { Nigeria, } \\
\text { Angola, } \\
\text { Congo }\end{array}$ & Yes & Poor \\
\hline Peragallo et al $2014^{29}$ & Yes & Not reported & M & M & Italy & Afghanistan & Yes & Poor \\
\hline Petersen et al $2000^{32}$ & Yes & Yes & $M, C$ & C & Denmark & Various & Yes & Good \\
\hline Petersen et al $2003^{40}$ & Yes & Not reported & A & M & Denmark & Eritrea & Yes & Good \\
\hline Rodrigues et al $2019^{35}$ & Yes & Yes & $M, A, D$ & C & Brazil & Various & Yes & Good \\
\hline Sanchez et al $2000^{22}$ & No & Not applicable & M & M & Brazil & Angola & No & Poor \\
\hline Saunders et al $2015^{25}$ & No & Not applicable & M, D & M & USA & Afghanistan & Yes & Poor \\
\hline Shady et al $2015^{38}$ & Yes & Yes & $M, D$ & C & Kuwait & Various & No & Good \\
\hline Sonmez et al $2005^{39}$ & No & Not applicable & $M, D$ & M & Turkey & Afghanistan & Yes & Poor \\
\hline Tan et al $2017^{30}$ & Yes & No & $M, A, D, C$ & M & USA & Various & No**** & Poor \\
\hline
\end{tabular}

Notes: *M-Mefloquine, A-Atovaquone/proguanil, C-Chloroquine, D-Doxycycline (data for any other groups in these studies using proguanil alone or chloroquine-proguanil combination was not analysed). **Assessment based on a modified NIH quality assessment tool for cross-sectional and cohort studies (Supplementary Material). ***Number of travelers stopping treatment due to adverse events were reported per drug.

study $=288$, IQ range $=41-1011$ ) in 20 studies. ${ }^{20-39}$ A total of 13,668 travelers reported the highest level of compliance in each study leading to a gross compliance rate of $80.59 \%$ (95\% CI=79.98-81.18). The refined compliance for mefloquine (from nine studies ${ }^{27,31-34,36-38}$ ) was $78.6 \%(1,234 /$ 1,570, 95\% CI=76.47-80.59). The percentage of travelers reporting any adverse event during prophylaxis (reported in 11 studies $\left.^{21,24-26,28,29,31,35,37,39}\right)$ was $23.8 \%(2,802 / 11,771$, 95\% CI=23.04-24.58). The percentage of travelers stopping treatment due to adverse events was reported in 10 studies $^{21,25,26,28-31,33,35,37}$ and stood at 5.51\% (585/10,610, 95\% $\mathrm{CI}=5.09-5.97)$.

\section{Chloroquine}

Chloroquine prophylaxis is still recommended for some destinations with chloroquine-sensitive vivax malaria. The adult dose for chemoprophylaxis is $300 \mathrm{mg}$ (base) weekly, starting 1-2 weeks before travel and ending 4 weeks after travel. Only three studies ${ }^{20,30,32}$ had data on stand-alone chloroquine for chemoprophylaxis with gross compliance of $60.64 \%(1,171 / 1,931,95 \% \mathrm{CI}=58.42-62.82)$. The refined 
compliance (calculated from one study ${ }^{32}$ ) was $78.5 \%$ (960/ $1,223)$. Only one study ${ }^{32}$ reported on the number of adverse events $(184 / 1,223,15.04 \%)$, while two studies ${ }^{30,32}$ reported a total of 64 people stopping chemoprophylaxis due to adverse events $(64 / 1,891,3.38 \%)$.

\section{Daily Prophylaxis}

\section{Atovaquone-Proguanil (Malarone)}

One tablet daily of this fixed dose combination (250/100 mg) is recommended to be started 1-2 days before travel, until 7 days after travel. Data from 11 studies $^{23,24,27,30,34-37,40-42}$ show that Atovaquone-proguanil was prescribed to a total of 2,257 (median per study=104, IQR=44-300) travelers with 1,600 demonstrating the highest level of compliance in each study (gross compliance $=70.89 \%, 95 \% \mathrm{CI}=68.96$ 72.75). The refined compliance (calculated from seven studies $\left.^{27,34-37,40,41}\right) \quad$ was $57.18 \% \quad(705 / 1,233, \quad 95 \%$ $\mathrm{CI}=54.36-59.96)$. Six studies ${ }^{24,35,37,40-42}$ reported a total of 301 people with adverse events out of 1,287 (23.39\%, 95\% $\mathrm{CI}=21.12-25.82$ ). A total of 15 people out of 1,289 (in five studies $^{30,35,40-42}$ ) stopped prophylaxis due to adverse events $(1.16 \%, 95 \%$ CI $=0.67-1.95)$.

\section{Doxycycline}

The usual chemoprophylactic dose of doxycycline is $100 \mathrm{mg}$ daily, to be started 1-2 days before travel and continued until 4 weeks after travel. In 13 studies, ${ }^{20,21,23-25,30,34-39,43}$ doxycycline was prescribed to a total of 3,886 people (median per study $=70, I Q R=34-438$ ), and 1,757 reported the highest tier of compliance assessed (gross compliance $=45.21 \%, 95 \%$ $\mathrm{CI}=43.64-46.79$ ). The refined compliance (calculated from five studies ${ }^{34-38}$ ) was $71.97 \%$ (339/471, 95\% CI=67.64 $75.94)$. A total of 1,177 people out of $2,411(48.82 \%, 95 \%$ $\mathrm{CI}=46.81-50.84$ ) had adverse events (as reported in six studies $^{21,24,25,35,37,39}$ ). A total of 254 people out of 2,290 (in three studies ${ }^{25,30,35}$ ) stopped prophylaxis due to adverse events $(11.09 \%, 95 \%$ CI=9.85-12.46).

\section{Cross Comparisons}

Comparing compliance across individual drugs has little clinical value as these drugs are prescribed after considering a variety of factors (parasite resistance at destination, patient preference, clinical judgment, and national guidelines) which may be more important than the presumed likelihood of patient compliance. However, we compared the gross and refined compliance to weekly administered drugs vs daily administered drugs and found that compliance was significantly higher for weekly schedules (gross compliance: $14,839 / 18,890$ vs $3,357 / 6,143, P<0.00001$, refined compliance: $2,194 / 2,793$ vs $1,044 / 1,704$, $P<0.00001)$. Refined compliance was significantly higher $(P<0.00001)$ than gross compliance for doxycycline, while the reverse was true for atovaquone-proguanil $(P<0.00001)$. There was no statistically significant difference between the two compliance statistics for mefloquine. Stopping the drug due to adverse events was more likely with doxycycline than with mefloquine $(P<0.0001)$ or atovaquone-proguanil $(P<0.0001)$. Those on atovaquoneproguanil were less likely to discontinue than those on mefloquine $(P<0.0001)$. We did not compare chloroquine in this regard as it is unlikely to be an effective alternative for other drugs due to chloroquine resistance prevalent in many countries. Ten studies ${ }^{22-25,28-30,39,40,43}$ reported data on military personnel and the gross compliance in military with any of the chemoprophylactic agents was significantly worse than in civilian travelers $(10,579 / 16,146$ vs $7,617 / 8,887, P<0.0001)$. The same was true on discontinuing prophylaxis due to adverse events (778/12,939 vs $140 /$ $3,141, P=0.0008)$. However, the proportion of doxycycline and mefloquine recipients were disproportionately high in the military $(3,298 / 16,146$ vs $588 / 8,887$ for doxycycline, $11,556 / 16,146$ vs $5,403 / 8,887$ for mefloquine, $P<0.0001$ ), while atovaquone-proguanil recipients were significantly high in the civilian travelers $(624 / 16,146$ vs $1,633 / 8,887$, $P<0.0001)$.

\section{Other Factors Influencing Compliance}

Eleven studies each had recorded participant responses on reasons for missing doses of chemoprophylaxis and statistical associations (adjusted or unadjusted odds ratios) for poor compliance. ${ }^{20,21,23,24,27,28,31,34,35,37-39}$ Due to the high heterogeneity in reporting (various definitions of compliance) and lack of consistency in selecting independent variables (eg, age groups, travel destinations) it is not possible to derive summary statistics for these. Instead, we describe the results narratively.

As for self-reported reasons for missing chemoprophylaxis, the recurring themes were forgetfulness (eight studies), ${ }^{20,24-26,29,33,39,40}$ experienced or anticipated adverse events (eight studies), ${ }^{20,24-26,28,29,33,39}$ perceived uselessness of prophylaxis (six studies, including responses such as "no mosquitoes at destination", locals advice that it is not necessary). ${ }^{26,29,33,40-42}$ Recurring significant associations with better compliance were older age (five studies), ${ }^{21,23,24,31,34}$ perceived level of vulnerability or severity of malaria (four studies), ${ }^{20,23,24,34}$ shorter period of travel 
or deployment (five studies), ${ }^{21,24,27,31,34}$ being on mefloquine (four studies), 20,21,27,38 and the destination being an African country (three studies). ${ }^{27,34,38}$ Some other associations for better compliance were inconsistently observed (eg, female gender, inverse relationship with level of education, traveling for leisure, organized travel vs spontaneous travel).

\section{Discussion}

In this study we explored the self-reported compliance of non-immune travelers for malaria chemoprophylaxis under "real-life" circumstances outside the context of randomized controlled trials (and of studies having interventions to boost compliance). Under these circumstances, the gross compliance was greater than $60 \%$ for all drugs except doxycycline. We also demonstrate that weekly administered regimens led to better compliance than daily administered regimens. Military travelers had worse compliance than civilian travelers, but this may be confounded by the type of prophylactic agent prescribed. Older age, perceived level of risk or severity of malaria, being on mefloquine, and shorter duration of travel were statistically significant associations with better compliance, as identified in four or more separate studies.

The data presented in this paper needs to be interpreted carefully. First, the choice of prophylaxis for a client should not entirely depend on historical compliance data of others. Instead, that choice should be guided by the effectiveness of the drug at the destination and patientrelated factors (preferences and contraindications). ${ }^{5}$ This paper does not evaluate the effectiveness of each drug as such recommendations change with time and prescribers must adhere to the local and international guidelines in existence at the time of prescription. However, when there is a choice of equally effective prophylactic agents, the data presented in this paper may help to make an informed choice to maximize compliance. More specifically, weekly prophylaxis may be better than daily prophylaxis. However if daily prophylaxis is considered, atovaquoneproguanil combination may be better than doxycycline provided it is effective at the destination, and safe to be prescribed (eg, atovaquone-proguanil is contraindicated in pregnant women, young children, and those with renal impairment). ${ }^{5}$

Civilian travelers had better compliance than military travelers, but, as already mentioned, this is confounded by the type of drug prescribed (the proportion of servicemen and women receiving doxycycline was significantly higher than in civilian travelers). Also, military travelers are deployed overseas for longer periods. This, plus the nature of deployment (eg, being in a combat zone), may increase the overall risk of non-compliance than in civilian travelers. Interestingly, none of the studies on military travelers mentioned stress of combat or deployment as a reason for non-compliance. However, this may be included when "forgetfulness" is cited as a reason for missing doses.

Regarding adverse events, we chose not to analyze each type of adverse event reported (eg, gastrointestinal, neuropsychiatric) as all data in these studies are derived from self-report of travelers. Their uptake of chemoprophylaxis was not verified, and some were interviewed months after completing travel leading to a high risk of recall bias. Thus, it is difficult to establish if reported events were in fact due to the chemoprophylaxis. Given the sensitivity around mefloquine and neuropsychiatric adverse events, ${ }^{44}$ plus the fact that some studies reported travelers not taking prophylaxis due to "perceived risk" of adverse events (not because they experienced these), we decided to not report data we cannot reliably verify. Such detailed analysis of adverse events should be done in context of a systematic review of randomized placebocontrolled double-blind clinical trials. However, stopping a drug due to perceived adverse events is a memorable event that is less likely to be influenced by recall bias and hence, if this data was reported, it was extracted and analyzed in this paper.

Out of the recurring themes for not taking prophylaxis, the most prominent ones were forgetfulness and adverse events. However, the percentage of travelers stopping chemoprophylaxis after experiencing adverse events was relatively small. Several studies reported that people had stopped taking prophylaxis due to fear of adverse events without experiencing it themselves. Cost of prophylaxis was mentioned as a deterrent in only two studies and is unlikely to be a problem for many short-term travelers. However, in many countries, the cost of atovaquone-proguanil may be higher than other alternatives. In addition to self-reported reasons for non-compliance, investigators also found several associations for better compliance, as mentioned in the results section. However, some of these associations may have a confounding effect on each other and not all studies reported adjusted odds ratios. For example, better compliance was associated with perceived level of risk or severity of malaria, mefloquine, and having an African destination. Indeed, for most African countries, the preferred prophylactic agent is mefloquine and the risk of severe malaria is also high due to widely prevalent 
falciparum malaria. Hence, the underlying theme for all three associations may be having an African destination.

Finally, the quality of evidence from each study needs to be weighed in when estimating the "true" compliance. When subgroup analysis was done with data from studies that were categorized as having "good" quality evidence, the compliance statistics (refined compliance) were significantly better for doxycycline, worse for atovaquone-proguanil, and had no difference for mefloquine compared to gross compliance. Notably the sample sizes for refined compliance calculations were considerably less as few military studies with large sample sizes could not meet the essential criteria to rank as "good quality" in the quality assessment. In this manuscript we report both compliance statistics (refined and gross) for the reader to judge the uncertainty in compliance estimates in the context of data quality.

This study had several limitations, and some have been already flagged (bias in data reporting due to self-report, recall bias, difficulty in causally linking adverse events to chemoprophylaxis, heterogeneity in defining compliance, some studies not assessing full period of chemoprophylaxis). We have attempted to mitigate some of these by classifying the studies as having "good" and "poor" quality evidence to report two compliance statistics in a subgroup analysis. We excluded studies with travel prior to 1995 as resistance patterns (and hence recommendations) would have been different to current circumstances a quarter century ago. However, this cut-off is arbitrary and there may be other studies that assessed the same prophylactic agents prior to 1995 . Another limitation is that self-report data of compliance may not tally with actual compliance. This was highlighted in the study by Landry et al, ${ }^{31}$ where self-report data on compliance was corroborated by simultaneous monitoring of drug use with an electronic pillbox. Though the actual compliance (number of pills used) was largely similar to the reported compliance, the timing of drug administration showed significant deviations from expected practice. Finally, we did not find any studies that assessed the acceptability of primaquine and tafenoquine under real-world circumstances. Primaquine has been available for over 60 years now and its efficacy for primary prophylaxis has been demonstrated in randomized clinical trials. ${ }^{4,8,45}$ Tafenoquine is a newer alternative to primaquine recently licensed in the USA and Australia (in 2018) for primary prophylaxis. ${ }^{46}$ Both can precipitate hemolysis in individuals with G6PD enzyme deficiency (hence testing is needed before prescription) and are contraindicated in pregnancy. ${ }^{6}$ These issues plus the need for daily administration may preclude primaquine as a preferred agent for primary prophylaxis. However, tafenoquine is new to the market and can be taken weekly and if taken for primary prophylaxis serves the dual function in providing terminal prophylaxis cover against $P$. vivax hypnozoites. Hence whether the acceptance of tafenoquine by travelers is better needs to be monitored in the future.

\section{Conclusion}

The choice of chemoprophylaxis for a non-immune traveler visiting an endemic region should primarily be based on current evidence-based guidelines on efficacy and patient-related factors such as contraindications and preference. However, evidence presented here shows that if a choice is available, travelers are more likely to comply with weekly dosing regimens than daily regimens. Historical data also suggests that stopping prophylaxis due to adverse events is more likely with doxycycline compared to mefloquine and atovaquone/proguanil. These facts could help in discussions with clients in travel clinics to select a suitable primary chemoprophylactic agent against malaria.

\section{Abbreviations}

CDC, Centers for Disease Control; NHLBI, National Heart, Lung, and Blood Institute.

\section{Consent for Publication}

This article does not have any copyrighted material.

\section{Author Contributions}

All authors made substantial contributions to the conception and design, acquisition of data, or analysis and interpretation of data; took part in drafting the article or revising it critically for important intellectual content; agreed to submit to the current journal; gave final approval of the version to be published; and agree to be accountable for all aspects of the work.

\section{Funding}

CR is supported by an NHMRC (Australia) investigator grant (number: 1173666).

\section{Disclosure}

The authors have no competing interests to declare. 


\section{References}

1. World Health Organization. World Malaria Report 2019. Geneva, Switzerland: WHO; 2020.

2. Fernando SD, Ranaweera D, Weerasena MS, et al. Success of malaria chemoprophylaxis for outbound civil and military travellers in prevention of reintroduction of malaria in Sri Lanka. Int Health. 2020;12 (4):332-338. doi:10.1093/inthealth/ihz094

3. Fernando SD, Rodrigo C, Rajapakse S. Chemoprophylaxis in malaria: drugs, evidence of efficacy and costs. Asian Pac J Trop Med. 2011;4(4):330-336. doi:10.1016/S1995-7645(11)60098-9

4. Hill DR, Baird JK, Parise ME, Lewis LS, Ryan ET, Magill AJ. Primaquine: report from CDC expert meeting on malaria chemoprophylaxis I. Am J Trop Med Hyg. 2006;75(3):402-415. doi:10.4269/ ajtmh.2006.75.402

5. Centers for Disease Control and Prevention. CDC Yellow Book: Health Information for International Travel. New York: Oxford University Press; 2020.

6. Rodrigo C, Rajapakse S, Fernando SD. Tafenoquine for primary and terminal prophylaxis of malaria in apparently healthy people: a systematic review. Trans R Soc Trop Med Hyg. 2019;113(10):579-586. doi:10.1093/trstmh/trz052

7. Lau CL, Ramsey L, Mills LC, Furuya-Kanamori L, Mills DJ. Drugfree holidays: compliance, tolerability, and acceptability of a 3-day atovaquone/proguanil schedule for pretravel malaria chemoprophylaxis in australian travelers. Clin Infect Dis. 2019;69(1):137-143. doi:10.1093/cid/ciy854

8. Baird JK, Lacy MD, Basri H, et al. Randomized, parallel placebo-controlled trial of primaquine for malaria prophylaxis in Papua, Indonesia. Clin Infect Dis. 2001;33(12):1990-1997. doi:10.1086/324085

9. Camus D, Djossou F, Schilthuis HJ, et al. Atovaquone-proguanil versus chloroquine- proguanil for malaria prophylaxis in nonimmune pediatric travelers: results of an international, randomized, open-label study. Clin Infect Dis. 2004;38(12):1716-1723. doi:10.1086/421086

10. Croft AM, Clayton TC, World MJ. Side effects of mefloquine prophylaxis for malaria: an independent randomized controlled trial. Trans R Soc Trop Med Hyg. 1997;91(2):199-203. doi:10.1016/ S0035-9203(97)90223-6

11. Fernando D, de Silva D, Carter R, Mendis KN, Wickremasinghe R. A randomized, double-blind, placebo-controlled, clinical trial of the impact of malaria prevention on the educational attainment of school children. Am J Trop Med Hyg. 2006;74(3):386-393. doi:10.4269/ ajtmh.2006.74.386

12. Ling J, Baird JK, Fryauff DJ, et al. Randomized, placebo-controlled trial of atovaquone/proguanil for the prevention of Plasmodium falciparum or Plasmodium vivax malaria among migrants to Papua, Indonesia. Clin Infect Dis. 2002;35(7):825-833. doi:10.1086/342578

13. Michel R, Bardot S, Queyriaux B, Boutin JP, Touze JE. Doxycyclinechloroquine vs. doxycycline-placebo for malaria prophylaxis in nonimmune soldiers: a double-blind randomized field trial in sub-Saharan Africa. Trans R Soc Trop Med Hyg. 2010;104(4):290297. doi:10.1016/j.trstmh.2009.10.001

14. Nasveld PE, Edstein MD, Brennan L, et al. Randomized, doubleblind study of the safety, tolerability, and efficacy of tafenoquine versus mefloquine for malaria prophylaxis in nonimmune subjects. Antimicrob Agents Chemother. 2010;54(2):792-798. doi:10.1128/ AAC.00354-09

15. Ohrt C, Richie TL, Widjaja H, et al. Mefloquine compared with doxycycline for the prophylaxis of malaria in Indonesian soldiers. A randomized, double-blind, placebo- controlled trial. Ann Intern Med. 1997;126(12):963-972. doi:10.7326/0003-4819-126-12-199706 150-00006

16. Soto J, Toledo J, Luzz M, Gutierrez P, Berman J, Duparc S. Randomized, double-blind, placebo-controlled study of Malarone for malaria prophylaxis in non-immune Colombian soldiers. Am J Trop Med Hyg. 2006;75(3):430-433. doi:10.4269/ajtmh.2006.75.430
17. Fontanet AL, Houze S, Keundjian A, et al. Efficacy of antimalarial chemoprophylaxis among French residents travelling to Africa. Trans $R$ Soc Trop Med Hyg. 2005;99(2):91-100. doi:10.1016/j.trstmh.2004.01.006

18. Ben-Ami R, Siegman-Igra Y, Anis E, et al. Malaria in travelers returning from short organized tours to holiday resorts in Mombassa, Kenya. Isr Med Assoc J. 2005;7(6):364-367.

19. National Institutes of Health. Study quality assessment tools; 2020. Available from: https://www.nhlbi.nih.gov/health-topics/study-qual ity-assessment-tools. Accessed August 15, 2020.

20. Laver SM, Wetzels J, Behrens RH. Knowledge of malaria, risk perception, and compliance with prophylaxis and personal and environmental preventive measures in travelers exiting Zimbabwe from Harare and Victoria Falls International airport. J Travel Med. 2001;8 (6):298-303. doi:10.2310/7060.2001.23975

21. Lobel HO, Baker MA, Gras FA, et al. Use of malaria prevention measures by North American and European travelers to East Africa. $J$ Travel Med. 2001;8(4):167-172. doi:10.2310/7060.2001.22206

22. Sanchez JL, Bendet I, Grogl M, et al. Malaria in Brazilian military personnel deployed to Angola. J Travel Med. 2000;7(5):275-282. doi: $10.2310 / 7060.2000 .00077$

23. Frickmann H, Schwarz NG, Holtherm HU, et al. Compliance with antimalarial chemoprophylaxis in German soldiers: a 6-year survey. Infection. 2013;41(2):311-320. doi:10.1007/s15010-013-0411-5

24. Landman KZ, Tan KR, Arguin PM. Adherence to malaria prophylaxis among Peace Corps Volunteers in the Africa region, 2013. Travel Med Infect Dis. 2015;13(1):61-68.

25. Saunders DL, Garges E, Manning JE, et al. Safety, tolerability, and compliance with long-term antimalarial chemoprophylaxis in American Soldiers in Afghanistan. Am J Trop Med Hyg. 2015;93 (3):584-590. doi:10.4269/ajtmh.15-0245

26. Matsumura T, Fujii T, Miura T, et al. Questionnaire-based analysis of mefloquine chemoprophylaxis for malaria in a Japanese population. $J$ Infect Chemother. 2005;11(4):196-198. doi:10.1007/s10156-005-03 90-2

27. Belderok SM, van den Hoek A, Roeffen W, Sauerwein R, Sonder GJB. Adherence to chemoprophylaxis and plasmodium falciparum anti-circumsporozoite seroconversion in a prospective cohort study of Dutch Short-Term Travelers. PLoS One. 2013;8(2):e56863. doi:10. 1371/journal.pone. 0056863

28. Fujii T, Kaku K, Jelinek T, Kimura M. Malaria and mefloquine prophylaxis use among Japan ground self-defense force personnel deployed in East Timor. J Travel Med. 2007;14(4):226-232. doi:10.1111/j.1708-8305.2007.00122.x

29. Peragallo MS, Sarnicola G, Boccolini D, Romi R, Mammana G. Risk assessment and prevention of malaria among Italian troops in Afghanistan, 2002 to 2011. J Travel Med. 2014;21(1):24-32. doi: $10.1111 / \mathrm{jtm} .12046$

30. Tan KR, Henderson SJ, Williamson J, et al. Long term health outcomes among returned peace corps volunteers after malaria prophylaxis, 1995-2014. Travel Med Infect Dis. 2017;17:50-55. doi:10.10 16/j.tmaid.2017.05.003

31. Landry P, Iorillo D, Darioli R, Burnier M, Genton B. Do travelers really take their mefloquine malaria chemoprophylaxis? Estimation of adherence by an electronic pillbox. J Travel Med. 2006;13(1):814. doi:10.1111/j.1708-8305.2006.00005.x

32. Petersen E, Ronne T, Ronn A, Bygbjerg I, Larsen SO. Reported side effects to chloroquine, chloroquine plus proguanil, and mefloquine as chemoprophylaxis against malaria in Danish travelers. $J$ Travel Med. 2000;7(2):79-84. doi:10.2310/7060.2000.00026

33. Hoebe C, de Munter J, Thijs C. Adverse effects and compliance with mefloquine or proguanil antimalarial chemoprophylaxis. Eur J Clin Pharmacol. 1997;52(4):269-275. doi:10.1007/s002280050288

34. Hoefnagel JGM, Massar K, Hautvast JLA. Non-adherence to malaria prophylaxis: the influence of travel-related and psychosocial factors. $J$ Infect Public Health. 2020;13(4):532-537. doi:10.1016/j.jiph.20 19.10.004 
35. Rodrigues KMD, da Costa ABF, Santoro-Lopes G. Adherence to malaria prophylaxis among travelers from a middle-income country. Rev Soc Bras Med Trop. 2019;52. doi:10.1590/0037-8682-0014-2019

36. Mavrogordato A, Lever AM. A cluster of Plasmodium vivax malaria in an expedition group to Ethiopia: prophylactic efficacy of atovaquone/proguanil on liver stages of P. vivax. J Infect. 2012;65(3):269 274. doi:10.1016/j.jinf.2012.04.015

37. Goodyer L, Rice L, Martin A. Choice of and adherence to prophylactic antimalarials. J Travel Med. 2011;18(4):245-249. doi:10.1111/ j.1708-8305.2011.00534.x

38. Shady I. Determinants of adherence with malaria chemoprophylactic drugs used in a traveler's health clinic. $J$ Trop Med. 2015;2015:163716. doi:10.1155/2015/163716

39. Sonmez A, Harlak A, Kilic S, et al. The efficacy and tolerability of doxycycline and mefloquine in malaria prophylaxis of the ISAF troops in Afghanistan. J Infect. 2005;51(3):253-258. doi:10.1016/j. jinf.2005.01.014

40. Petersen E. The safety of atovaquone/proguanil in long-term malaria prophylaxis of nonimmune adults. J Travel Med. 2003;10(SUPPL.1): S13-S15. doi:10.2310/7060.2003.35050

41. DePetrillo JC, Singer C, Bergagnini IA, Kolakowski P, Edwards B, Smith MA. Assessment of adherence to atovaquone-proguanil prophylaxis in travelers. J Travel Med. 2010;17(4):217-220. doi:10.11 11/j.1708-8305.2010.00426.x
42. Nicosia V, Colombo G, Consentino M, et al. Assessment of acceptability and ease of use of atovaquone/proguanil medication in subjects undergoing malaria prophylaxis. Ther Clin Risk Manag. 2008;4 (5):1105-1110. doi:10.2147/TCRM.S3782

43. Bellanger AP, Faucher JF, Robedat P, Schmitt A, Millon L, Hoen B. Malaria outbreak in French troops returning from Cote d'Ivoire. Scand J Infect Dis. 2011;43(3):230-233. doi:10.3109/00365548. 2010.538857

44. Grabias B, Kumar S. Adverse neuropsychiatric effects of antimalarial drugs. Expert Opin Drug Saf. 2016;15(7):903-910. doi:10.1080/ 14740338.2016.1175428

45. Fryauff D, Baird K, Basri H, et al. Randomised placebo-controlled trial of primaquine for prophylaxis of falciparum and vivax malaria. Lancet. 1995;346(8984):1190-1193. doi:10.1016/S0140-6736(95) 92898-7

46. Frampton JE. Tafenoquine: first global approval. Drugs. 2018;78 (14):1517-1523. doi:10.1007/s40265-018-0979-2
Patient Preference and Adherence

\section{Publish your work in this journal}

Patient Preference and Adherence is an international, peer-reviewed, open access journal that focusing on the growing importance of patient preference and adherence throughout the therapeutic continuum. Patient satisfaction, acceptability, quality of life, compliance, persistence and their role in developing new therapeutic modalities and compounds to optimize clinical outcomes for existing disease

\section{Dovepress}

states are major areas of interest for the journal. This journal has been accepted for indexing on PubMed Central. The manuscript management system is completely online and includes a very quick and fair peer-review system, which is all easy to use. Visit http:// www.dovepress.com/testimonials.php to read real quotes from published authors. 